\title{
AVALIAÇÃo DA PROVA DA DIGESTÃo DA CELULOSE NO LÍOUIDO RUMINAL DE OVINOS DAS RAÇAS MERINO AUSTRALIANO E CORRIEDALE, CRIADOS EM REGIME EXTENSIVO DE PASTAGEM
}

\author{
EVALUATION OF THE CELLULOSE DIGESTION IN RUMEN LIOUOR FROM AUSTRALIAN \\ MERINO AND CORRIEDALE SHEEP, FED ON PASTURE
}

Francisco Leydson Formiga FEITOSA'; Clóvis Telxeira de ALMEIDA'; Mary Marcondes FEITOSA'; Paulo Roberto CUR P

\begin{abstract}
RESUMO
Realizou-sc a prova da digestão da celulose no líquido ruminal de ovinos das raças Mcrino Australiano c Corricdale, criados $\mathrm{cm}$ regime extensivo de pastagem, em duas épocas do ano (inverno e verāo), no município de Botucatu - Såo Paulo. Foram utilizados 103 animais no inverno, sendo 50 ovelhas da raça Corricdale e 53 da raça Merino Australiano, e 107 animais no verão, com 52 ovelhas pertencentes à raça Corricdale c 55 à raça Merino Australiano. As amostras foram obtidas por meio de sonda csofágica. A degradação da celulose não ocorreu na maioria das amostras analisadas, não sc observando diferenças entre as raças $\mathrm{c}$ as estaçōes do ano.
\end{abstract}

UNITERMOS: Cclulose, digestibilidadc; Rumen, nluidos; Digestão, ovinos; Mcrino Australiano; Corricdale

\section{INTRODUÇĀO}

BAUMGARTNER' (1983) relatou que o exame clínico dos movimentos motores no compartimento pré-estomacal, juntamente com a avaliação do líquido ruminal, permitem um maior controle sobrc a digestão microbiológica c bioquímica no compartimento rúmino-rcticular' ${ }^{1}$. Desse modo, o exame laboratorial do suco de rúmen é essencial para promover o diagnóstico das alteraçð̌es da digestão nos pré-estômagos, contribuindo não só para o estabclecimento de um determinado tratamento, como também para a avaliaçāo de sua eficácia.

Apesar da litcratura referente à avaliação do líquido ruminal $\mathrm{em}$ bovinos ser relativamente extensa, existe uma grande limitação no estudo do suco de rúmen de ovinos criados $\mathrm{cm}$ nossas condiçőcs climáticas c de mancjo, já que a maioria dos trabalhos cicntíficos foi realizada $\mathrm{cm}$ outros paíscs. Visando precncher parte desta lacuna, este trabalho foi planejado com o objetivo de cstabclecer padröes de referência para a digeståo da cclulose $\mathrm{cm}$ ovinos clinicamente sadios, das raças Merino Australiano c Corricdale, criados $\mathrm{cm}$ regime de pasta$\mathrm{gcm}$, verificar as possivveis mudanças dessas variáveis com relação à época do ano c obscrvar a cxistência de variaçð̌s cntre raças nas duas épocas do ano.

\section{MATERIAL E MÉTODO}

\section{Animais Utilizados}

Este trabalho foi realizado na Fazenda Edgardia, de propricdade da Faculdade de Medicina Vetcrinária e Zoolecnia, UNESP, na cidade de Botucatu, Estado de São Paulo. Foram utilizados 103 animais no inverno, sendo 50 ovelhas da raça Corricdale c 53 da raça Merino Australiano, c 107 animais no verăo, com 52 ovelhas pertencentes à raça Corricdalc e 55 à raça Mcrino Australiano. Os animais aprescntavam idade entre dois $\mathrm{c}$ quatro anos $\mathrm{c}$ cram submetidos a uma dicta básica de forragem verde ad libitum, desde o desmame, constituída exclusivamente de Cynodon dactylon (L) Pers. Antes do inicio do experimento os animais receberam tratamento antihelmíntico* $\mathrm{c}$ foram observados clinicamente a fim de comprovar o cstado de higidez do rebanho. Os animais utilizados no inverno foram posteriormente utilizados no verão, acrescidos de dois animais da raça Corriedale c dois da raça Merino Australiano.

\section{Colheita das Amostras}

As colhcitas das amostras foram realizadas $\mathrm{cm}$ sua maior parte nos meses de julho (inverno) do ano de 1990, e de janciro (verão) do ano de 1991, das 9:00 às 10:00 horas.

As amostras, variando de 400 a $500 \mathrm{ml}$ de líquido ruminal, foram obtidas mediante a introduçăo de uma sonda csofágica, adaplada a uma bomba de vácuo**, no rúmen (Fig. 1).

As amostras obtidas cram imediatamente transferidas para garrafas térmicas individuais, scgundo ZAMBRANO's (1975), previamente aquecidas com água à temperatura de $39^{\circ} \mathrm{C}$ is. As garrafas cram cntão imcdiatamentc fechadas, procurando-se, dessa mancira, cvitar mudanças bruscas na temperatura c contato com o ar atmosférico.

\section{Exame do Líquido Ruminal}

A prova da digestão da cclulose foi realizada de acordo com a tócnica de HOFLUND ct al. ${ }^{6}$ (1948). Um fio de algodão não mercerizado com um pequeno peso na extremidade cra colocado $\mathrm{cm}$ um tubo testc contendo $10 \mathrm{ml}$ de fluido ruminal $\mathrm{c}$ $0,3 \mathrm{ml}$ de uma solução de glicose a $16 \%$, observando-se,

1-Professor Assistente - Faculdade de Medicina Veterinária da UNESP - Campus de Araçatuba

2-Professor Assistente Doutor - Faculdade de Medicina Veterinária c Zootecnia da UNIESP - Campus de Bolucalu

3-Professor Titular - Faculdade de Medicina Vetcrinária e Zoolecnia da UNESP - Campus de Botucatu

- RIPERCOL INJET ÁVEL - Cynamid Química do Brasil

* BOMBA DE SUCÇスO RUMDNAL - H. Hauptner - Solingen 
FETTOSA, F.L.F.; ALMEIDA, C.T.; FETTOSA, M.M.; CURI, P. R. Avaliaçăo da prova da digestăo da celulose no líquido ruminal de ovinos das raças Merino Australiano e Corriedale, criados em regime extensivo de pastagern. Braz J. vet. Res. anlm. Sd., Sāo Paulo, v.29, P. 369-373, 1992. Suplernento.

entăo, o tempo necessário para que o fio fosse digerido. $O$ tubo teste com o fio foi mantido em estufa a $39^{\circ} \mathrm{C}$ até o fim do experimento.

\section{Análise Estatística}

As variáveis foram avaliadas nas duas raças (Corriedale e Merino Australiano), no inverno e verāo. Foram efetuados os seguintes procedimentos:

a) Estudo descritivo das variávcis por raça c cm cada época do ano, calculando-sc as proporçð̃es das ocorrências mais frequicntes.

b) Comparaçæo entre inverno c verð̄o (utilizando-se os animais avaliados nas duas épocas), pcla prova nåo paramétrica de Wilcoxon (SIEGEL ${ }^{14}$, 1975), para amostras parcadas, com o cálculo da estatística ${ }^{\mathrm{T}(14)}$.

c) Comparaçăo entre as raças Mcrino Australiano e Corricdalc, pela prova não paramétrica de Mann-Whitncy SIEGEL ${ }^{14}$, (1975), com o cálculo da estatística U c aproximação z para grandes amostras, utilizando-se todos os animais ${ }^{14}$.

\section{RESULTADOS}

TABELA 1

Número e proporça de animais onde ocorreu a degradacāo do fío de celulose (entre 48 e 72 horas) e número tolal de animais das raças Merino Australiano (MER) e Corriedale (CORR), no inverno (INV) e verão (VER). Botucatu, 1991.

\begin{tabular}{lccc}
\hline & Digestuo do fio & proporçāo & Total \\
\hline MER INV & 4 & 0,0755 & 53 \\
MER VER & 9 & 0,1636 & 55 \\
CORR INV & 2 & 0,0400 & 50 \\
CORR VER & 10 & 0,1923 & 52 \\
\hline
\end{tabular}

TABELA 2

Comparapoes estatísticas e níveis de probabilidade. Bolucatu, 1991.

\begin{tabular}{ll}
\hline Comparaçes & Estatistica \\
\hline MER x CORR no INV & $z=0,31 ; p>0,50$ \\
MER x CORR no VER & $z=0,96 ; p>0,30$ \\
INV $\times$ VER $p /$ MER & $T=19,5 ; p>0,10$ \\
INV x VER $p /$ CORR & $T=19,0 ; p>0,10$ \\
\hline
\end{tabular}

\section{DISCUSSĀO}

Os resultados obtidos na prova da digestão da cclulose confirmam as afirmaçoes de ROSENBERGER ${ }^{13}$ (1983), que considera o teste impreciso e muito demorado para a avaliaçăo da microflora cclulolítica ${ }^{13}$. A proporção de animais onde ocorreu a digestão da celulose foi muito pequena $\mathrm{cm}$ relação ao número total de amostras, c o tempo nccessário para a digestao foi de 48 a 72 horas, superior ao observado por HOFLUND ct al. ${ }^{6}$ (1948), que variou de 48 a 54 horas.

Segundo NICHOLS; PENN ${ }^{10}$ (1958) c BLOOD; RADOSTITS $^{3}$ (1989), um tempo de digestão superior a 30 horas deve ser um indício de anormalidade ${ }^{3,10}$. No presente experimento, apesar de não ter ocorrido a digestão do fio de celulose na maioria das amostras (Tab. 1) e da digestão ter demorado de 48 a 72 horas naquelas amostras onde ela ocorreu, năo se pode considerar os resultados como indicadores de uma anormalidade, já que todos os animais utilizados neste experimento eram clinicamente sadios.

Não foram constatadas diferenças estatisticamente significativas entre as raças Merino Australiano c Corriedale quanto à degradação da cclulose (Tab.2), ou porque clas realmente inexistem, ou devido ao pequeno número de amostras onde ocorreu a degradação do fio de celulose.

Há uma contradiçæo entre os relatos de CIPOLLONI et al. ${ }^{4}$ (1951), que afirmaram haver diferenças nos coeficientes de digestão da celulose entre bovinos e ovinos, e os relatos de QUICKE ct al. ${ }^{12}$ (1959), que realizaram estudos de digestão da cclulose, assumindo que os coeficientes eram os mesmos para as duas espécics animais 4,12. Comparando-se os dados obtidos no presente experimento com os dados obtidos por OLIVEIRA $^{\prime \prime}$ (1991), que realizou a mesma prova em bovinos, pode-sc concluir que existem diferenças significativas entre os coeficientes de degradação da celulose de bovinos e ovinos, já que os dois experimentos foram conduzidos nas mesmas épocas do ano, sob as mesmas condiçōes climáticas, e ambos com animais em regime extensivo de pastagem".

Um problema na utilização da celulose em forragens naturais e a diminuiçăo da sua degradação à medida que a forragem vai crescendo, como foi exposto por HUNGATE: (1981). Com isso, e de se esperar que a taxa de degradação da celulose in vivo seja maior nos meses de verão do que nos de inverno, mas isto não cra esperado no presente experimento, já que o fio de algodåo utilizado foi o mesmo nas duas estaçōes do ano. Em virtude do pequeno número de amostras onde ocorreu a digestão do fio de celulose, não foi possível constatar diferenças entre os meses de invemo c verăo (Tab. 2). Entretanto, devido ao maior número de bactérias no verāo, conforme DEHORITY; ORPIN' ${ }^{5}$ (1988), a digestão da celulose provavelmente scria mais acentuada nessa época do ano ${ }^{5}$.

Existem algumas objoçð̄es para se trabalhar com digeståo no fluido ruminal in vitro que precisam ser consideradas quando da interpretação de resultados e que, scmpre que possível, devem ser controladas pelas condiçðes experimentais. Quando a digestăo $\mathcal{E}$ rápida, como no caso da glicose, o experimento in vitro parcce scr bastante ficl à realidade. No entanto, quando a digestăo é lenta, como no caso da celulose, as condiçס̄es in vitro devem ser cuidadosamente verificadas para que permaneçam próximas do cstado físiológico. Por esse motivo, BENTLEY et al. $^{2}$ (1954); QUICKE ct al. ${ }^{12}$ (1959); ICHHPONANI; SIDHU ${ }^{9}$ (1964) e HUNGATE7 (1966) ressaltaram a importância de simular em laboratório as condiçðes existentes no rúmen, pela adiçåo de um meio nutriente ao fluido ruminal, do ajuste do $\mathrm{pH}$ próximo ao valor fisiológico no correr do experimento e da manutenção do meio $\mathrm{cm}$ anaerobiose $\mathrm{e}^{2,7,9,12}$. A ausência destas condiçớcs, no entanto, não parece ter sido responsável pela baixa digesıăo do fio de celulose neste experimento, uma vez que nos trabalhos de OLIVEIRA ${ }^{11}$ (1991) as condiçðes eram as mesmas e ocorreu a digestão do fio ".

\section{CONCLUSŌES}

Os resultados obtidos com a avaliação do líquido ruminal de ovinos das raças Merino Australiano e Corriedale nos meses de verão e invemo permitiram concluir que o teste da digestăo da celulose não demonstrou ser eficaz na avaliação da capacidade dos microrganismos $\mathrm{cm}$ digerir a celulose $\mathrm{em}$ ovinos. Além disso, esta prova dispende muito tempo para sua realização, o que inviabiliza a sua utilização na rotina clínica. 


\section{SUMMARY}

Evaluation of cellulose digestion was carricd out in rumen liquor from Australian Merino and Corriedale shecp, fed on pasture in two seasons of the year (winter and summer), in Botucatu City, São Paulo, Brazil. Ruminal samples were collected using a standard tube, from 103 sheep during the winter period ( 50 Corriedale and 53 Australian Merino) and from 107 sheep in the summer (52 Corriedale and 55 Australian Merino). The cellulose digestion did not occur in the very majority of samples, and no significant differences between brecds and seasons were observed.

UNITERMS: Cellulose, digestibility; Rumen fluids; shecp digestion, Australian, Corriedale

\section{REFERÊNCIAS BIBLIOGRÁFICAS}

01-BAUMGARTNER, W. Laboratory diagnosis in cattle practice $V$. Examination of rumen fluid. Tierärztl. Umsch., v. 38, p. 560 1, 1983.

02-BENTLEY, O. G.; JOHNSON, R. R.; VANECKO, S.; HUNT, C. $H$. Studies on factors needed by rumen micro-organisms for cellulose digestion in vitro. J.anim. Scl., v.13, p.581-93, 1954.

03-BLOOD, D. C.; RADOSTITS, O. M. Veterinary medicine: a textbook of the diseases of catle, sheep, pigs, goats and horses. 7. ed. London, Baillière Tindall, 1989. p. 228-87: Diseases of the alimentary tract.

04-CIPOLLONI, M.A.; SCHNEIDER, B.H.; LUCAS,H.L;PAVLECH, H.M. Significance of the differences in digestibility of feods by cattle and sheep. J. anim. Sci., v.10, p. 337-43, 1951.

OS-DEHORTY, B. A; ORPIN, C. G. Development of, and natural fluctuations in, numen microbial populations. In: HOBSON, P.N.The rumen microbial ecosystem. Amstcrdan, Elsevier, 1988.p. 151-83.
06-HOFLUND, S.; QUIN, J. I.; CLARK, R. Studies on the alimentary tract of Merino sheep in South Africa XV. The influence of ccllulose digestion (a) in the rumen and (b) in ruminal ingesta as studied in vitro. Onderstepoort J. vet. Scl. anIm. Ind., v. 23, p. 395-409, 1948.

07-HUNGATE, R.E. The rumen and its microbes. Ncw york, Academic Press, 1966.

08-HUNGATE, R.E. The role of rumen microbes in ruminant digestion. Indian J. vet. Med., v. 1, p. 1-20, 1981.

09-ICHHPONANI, J. S.; SIDHU, G. S. The digestion of cellulose by rumen micro-organisms. Indlan vet. J., v.41, p. 467-75, 1964.

10-NICHOLS, R. E.; PENN, K. E. Simple methods for the detection of unfavorable changes in ruminal ingesta. J. Amer. Vet. Med. Ass., v.133, p. 275-7, 1958.

11-OLIVEIRA, D. B. Estudo do suco ruminal de bovinos criados em regime extensivo de pastagem (Brachlaria decumbens) no municíplo de Botucatu - SP. Botucatu, UNESP, 1991. Disscrtaçảo (Mestrado) - Faculdade de Medicina Vetcrinária c Zootocnia, Universidade Estadual Paulista.

12-QUICKE, G. V.; BENTLEY, O. G.; SCOTT, H. W.; MOXON, A. L. Cellulose digestion in vitro as a measure of the digestibility of forage cellulose in ruminanis. J. anim. Scl., v.18, p. 275-87, 1959.

13-ROSENBERGER, G. Exame clínico dos bovinos. 2. cd. Rio de Janeiro, Guanabara Koogan, 1983.

14-SIEGEL, S. Estatística nāo paramétrica. São Paulo, Mc Graw Hill, 1975.

15-ZAMBRANO, A.F. H. Algumas provas funcionais do rúmen em bovinos submetidos a diferentes regimes allmentares. Belo Horizonte, UFMG, 1975. Disscrtação (Mestrado) - Escola de Veterinária, Universidade Federal de Minas Gerais.

Recebido para publicą̧ão cm 16/01/1992 Aprovado para publicação cm 12/08/1992 
Figura 1 - Material utilizado para obtençāo do líquido ruminal de ovinos.

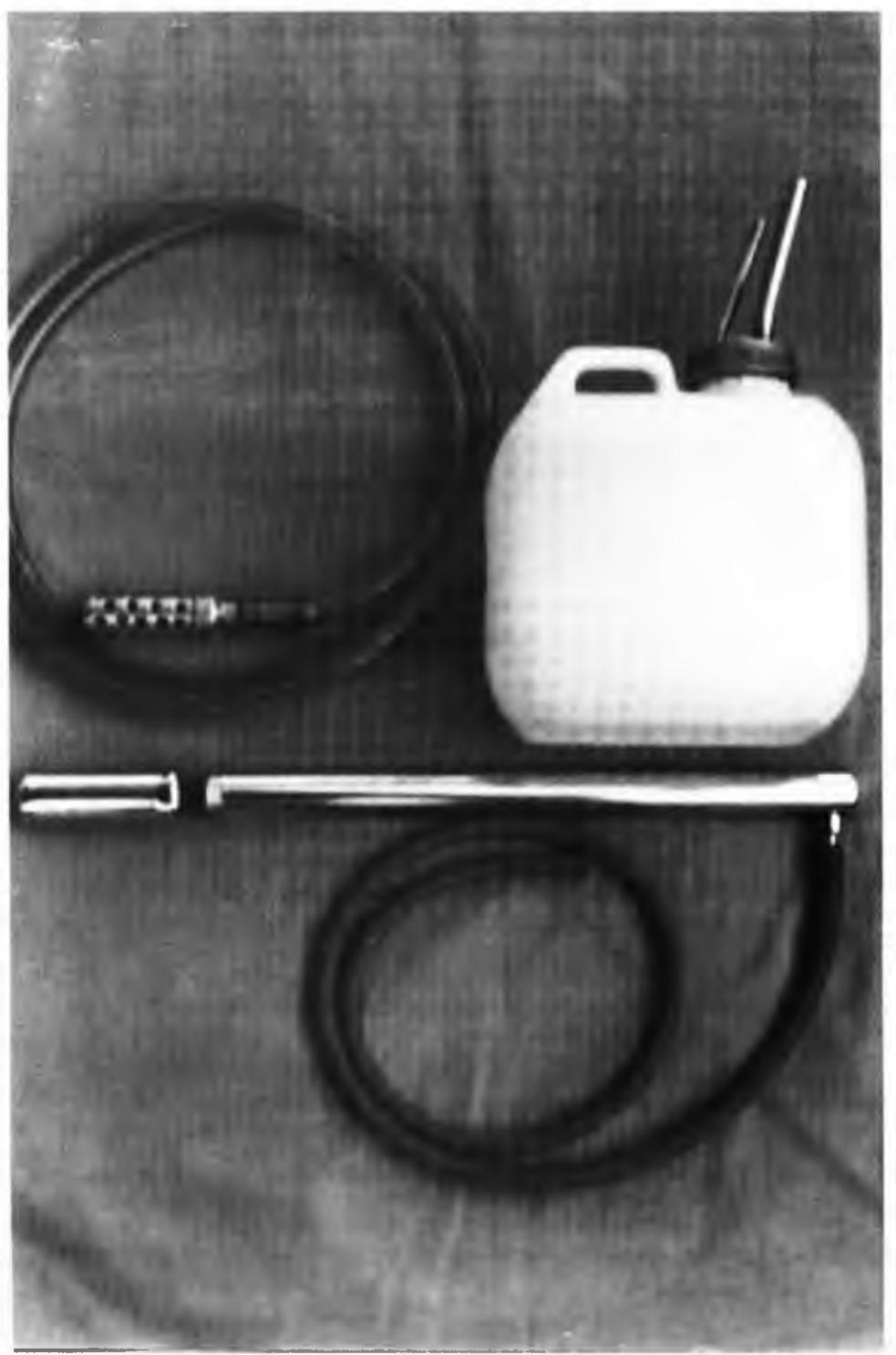

